\begin{tabular}{|c|l|}
\hline Title & $\begin{array}{l}\text { Magnetic susceptibility of dust-loaded leaves as a proxy of traffic-related heavy metal pollution in Kathmandu city, } \\
\text { Nepal }\end{array}$ \\
\hline Author(s) & Gautam, Pitambar; Blaha, Ulrich; A ppel, Erwin \\
\hline Citation & $\begin{array}{l}\text { Atmospheric environment, 39(12), 2201-2211 } \\
\text { https://loi.org/10.1016/.atmosenv.2005.01.006 }\end{array}$ \\
\hline Issue Date & 2005-04 \\
\hline Doc URL & http:/hdl.handle.net/2115/38427 \\
\hline Type & article (author version) \\
\hline File Information & Gautam-1.pdf \\
\hline
\end{tabular}

Instructions for use 


\title{
Magnetic susceptibility of dust-loaded leaves as a proxy of traffic-related heavy metal pollution in Kathmandu city, Nepal
}

\author{
Pitambar Gautam ${ }^{\mathrm{a},}$, , Ulrich Blaha ${ }^{\mathrm{b}}$ and Erwin Appel ${ }^{\mathrm{b}}$ \\ ${ }^{a}$ COE for Neo-Science of Natural History, Graduate School of Science, Hokkaido University N10 \\ W8, Sapporo 060-0810, Japan \\ ${ }^{b}$ Institute of Geosciences, University of Tübingen, 72076 Tübingen, Germany
}

*Corresponding author

E-mail: p-gautam@nature.sci.hokudai.ac.jp, pgautam2000@yahoo.com

FAX: +81 117062986

\begin{abstract}
Dust-loaded tree leaves from Kathmandu have been analyzed for magnetic susceptibility $(\chi)$ and heavy metal (HM) contents. For 221 samples of leaves of cypress (mainly Cupressus corneyana), silky oak (Grevillea robusta) and bottlebrush (Callistemon lanceolatus), $\chi$ has a range of (0.01 to 54) $\times 10^{-8} \mathrm{~m}^{3}$ $\mathrm{kg}^{-1}$ with a median of about $10.0 \times 10^{-8} \mathrm{~m}^{3} \mathrm{~kg}^{-1}$. Trees situated close to the busy road intersections, near main bus station and sectors of roads with steep slope yield elevated susceptibility.

Chemical analysis of 20 samples of varying susceptibility by atomic absorption spectrometry yields the following maximum HM contents: Fe (1.3 wt.\%), Mn (281.9 ppm), Zn (195.2 ppm), Cu (41.5 ppm), $\mathrm{Pb}$ (38.4 ppm), Ni (8.1 ppm), Cr (6.4 ppm), Co (4.1 ppm) and Cd (1.2 ppm). The logarithmic susceptibility on dry mass basis $\left(\chi_{\mathrm{d}}\right)$ shows significant linear relationship with HM contents: Pearson's correlation coefficient $r>0.8$ with $\mathrm{Zn}, \mathrm{Fe}, \mathrm{Cr} ; \mathrm{r}>0.7$ with $\mathrm{Mn}, \mathrm{Cu} ; \mathrm{r}>0.6$ with $\mathrm{Pb}, \mathrm{Ni}$. Magnetic phases are of soft (magnetite/maghemite) and hard (hematite) coercivities. Microscopy of magnetic extracts reveals spherules (mostly of 2-20 $\mu \mathrm{m}$ diameter) originated from vehicle exhausts through the combustion process as well as crystalline grains of lithogenic origin.

The dust accumulation in leaves took place mainly after the monsoon (beginning of October, 2001) till the sampling period (first half of February, 2002). Despite the dependence of susceptibility and HM contents on a variety of spatial and temporal factors (amount of particulate matter (PM), efficiency of deposition/removal of PM by wind, precipitation, birds etc.), a significant correlation of susceptibility to HM implies that the former serves as effective proxy of metallic pollution. Hence, susceptibility-based bio-monitoring technique is recommended as an economic and rapid tool for assessment of environmental pollution in urban areas like Kathmandu.
\end{abstract}

Keywords: Magnetic bio-monitoring; Dust loadings; Urban pollution; Environmental magnetism; Magnetic spherules

\section{Introduction}

Roadsides in urban area are commonly polluted by particulate matter (PM) derived mostly from traffic: motor vehicle emissions, abrasion of tyres, brake linings as well as road surface, cycling of dust in suspension due to vehicular movement, dispersion of construction material, etc. (Petrovsky and Ellwood, 1999; Gautam et al., 2004b). After its initial release into the atmosphere, PM may remain in air for some time, but most of it ultimately gets deposited along the narrow roadside corridor forming an integral part of the road dust, roadside soil, vegetation and drainage system. Hence, any material in and close to the road corridor serves as an archive of elevated concentrations of trace metals and their compounds. 
Knowledge on the nature of the metallic particles is important along with the concentration and size distributions, which are dictated by nature of emissions, the rates of wet and dry deposition, nature and intensity of atmospheric phenomena as well as chemical transformations (e.g. Fang et al., 2004).

The content of airborne PM may be expressed in terms of total mass of suspended particles (TSP). However, the mass of particles with aerodynamic diameters below $10 \mu \mathrm{m}\left(\mathrm{PM}_{10}\right)$ per unit volume has been in common use since its monitoring started in the US in 1987 (Samet et al., 2000). The inhalability of $\mathrm{PM}_{10}$ sized particles deep into the respiratory system causing adverse health effects, the higher rate of incidence of health problems with decrease in the particle size, association of the levels of fine PM in air with enhancement in morbidity and mortality rates and reduction in visibility etc. led to efforts to classify PM to even smaller size levels such as $\mathrm{PM}_{2.5}$ and $\mathrm{PM}_{1}$ (e.g. Samet et al., 2000; Palmgren et al., 2003).

The problem of vehicular pollution is relatively more severe in cities, like Kathmandu, in developing countries because of inadequate technical, economic as well as legislative provisions. High traffic density compared to the size and length of roads, predominance of old vehicles prone to high emission levels, poor quality of fuel and lubricants, late introduction of emission control standards and weaknesses in enforcing them and lack of fundamental database on emissions are the real problems. According to KEVA (2003), the annual average $\mathrm{PM}_{10}$ concentration in Kathmandu city in 2002-2003 was estimated at 198 $\mu \mathrm{g} / \mathrm{m}^{3}$ with a $\mathrm{PM}_{2.5}$ to $\mathrm{PM}_{10}$ ratio of 0.64 implying a high contribution from combustion sources. Several recent changes, e.g. introduction of unleaded gasoline in 1999, closure of the Himal cement factory in 2000, increasing tendency in replacement of the Bull's trench type kilns by new kilns with reduced emissions for brick production, use of kerosene and gas for cooking instead of biomass, have led to reduced pollution in Kathmandu. Because of a three-fold increase in the number of vehicles during the last decade, however, traffic emission has significantly increased and the vehicles are the number one source of pollution (KEVA, 2003).

Recent awareness to the rise in cases with respiratory diseases (e.g. chronic obstructive pulmonary disease, asthma) etc. led the Nepalese government to initiate programs to monitor PM and formulate the national ambient air quality standards in terms of a few parameters (TSP, $\mathrm{PM}_{10}, \mathrm{PM}_{2.5}, \mathrm{CO}, \mathrm{NO}_{2}, \mathrm{SO}_{2}$ and benzene) (NESS, 2001; KEVA, 2003; MOPE Nepal, 2004). Besides monitoring, we see an urgent need for characterization and quantification of the particles in differing environmental systems (atmosphere, soil, vegetation, water etc.) using rapid and cost-effective techniques, such as combined environmental magnetic and analytical chemical methods, similar to those applied in European countries (Petrovsky and Ellwood, 1999, Hoffmann et al. 1999; Hanesch and Scholger, 2002; Muxworthy et al., 2002).

This study is a part of the ongoing magnetic and geochemical investigations of urban material (soil, road dust and tree-leaves) to address the problems of environmental degradation of the Kathmandu valley subjected to accelerated urbanization (population overpressure by ca. 1.5 million people) and environmental stress (increasing traffic, industries etc.) (Gautam et al., 2004b). Studies related to the use of magnetic properties of tree leaves are not new. For example, effective use of susceptibility of conifer needles as pollution proxy was established in Germany by Schädlich et al. (1995) for an industrial region affected by fly ash deposition and by Knab et al. (2003) in an apparently clean area of Black Forest. Matzka and Maher (1999) found the isothermal remanent magnetization (IRM) imparted to leaves of birch (Betula pendule) in urban and suburban area, around the city of Norwich (UK), useful as a proxy of traffic pollution. Suitability of both susceptibility and IRM of dust-loaded leaves of deciduous trees (Platanus sp. and Quercus Ilex) for mapping vehicular traffic emissions in the city of Rome in Italy was described by Moreno et al. (2003). Similarly, Hanesch et al. (2003) demonstrated the potential of susceptibility and IRM to susceptibility ratio of maple tree leaves in and around an Austrian industrial site in Leoben for monitoring short-term (up to several months) dust deposition. Though the effectiveness of 
these methods is established, there exist no standards for the sampling material and study parameters.

This paper deals with the first magnetic bio-monitoring study, in Kathmandu, based on 3 types of trees, represented by cypress, silky oak, and bottlebrush, which collectively offer a good coverage in both urban and suburban areas. We describe the magnetic susceptibility of the tree leaves, the contents of heavy metals ( $\mathrm{HM}: \mathrm{Cd}, \mathrm{Cu}, \mathrm{Co}, \mathrm{Cr}, \mathrm{Fe}, \mathrm{Mn}, \mathrm{Ni}, \mathrm{Pb}, \mathrm{Zn}$ ), and the susceptibility vs. $\mathrm{HM}$ relationship to characterize and quantify the environmental pollution.

\section{Research Methodology}

\subsection{Sampling}

Leaves with dust loadings were sampled along road corridors as well as recreational parks in both urban and suburban areas in February 2002. Samples came from the following routes and areas (Fig. 1): (i) the western half of the Ring Road; (ii) inner roads between Kalanki and Koteshwar; (iii) the arterial roads leading to Kirtipur and Dakshinkali; and (iv) around the Ratna Park and Rani Pokhari, in the core urban areas.

We sampled a total of 221 trees represented by cypress (mainly Cupressus corneyana) found commonly along the inner city roads and gardens, silky oak (Grevillea robusta) that is abundant along the Ring Road, and bottlebrush (Callistemon lanceolatus) that fills large gaps between the former two species) (Figs. 1 and 2, Table 1). In the case of cypress, only the young tender leaves were taken. Whenever possible, sampling was confined to branches, facing road, at a height of $2-2.5 \mathrm{~m}$ above ground. Samples were put in pocket-sized sealable plastic bags, of known susceptibility, and allowed to dry at room temperature, before measuring them in the laboratory.

\subsection{Susceptibility measurement, IRM acquisition and microscopy}

Volume magnetic susceptibility was measured on the AGICO KLY-2 Kappabridge, with an operating frequency of $920 \mathrm{~Hz}$ and sensitivity of $4 \times 10^{-8} \mathrm{SI}$. For intra-species and inter-species comparisons, it was then normalized by the sample mass to obtain the mass-specific susceptibility $(\chi)$.

A small amount of dust-loaded leaf sample was inserted into a $10 \mathrm{cc}$ volume polyethylene cylinder, fixed with nonmagnetic cement slurry, solidified, and then subjected to IRM acquisition up to a maximum of $2.5 \mathrm{~T}$, using pulse fields at 18-20 steps generated by a Magnetic Measurements pulse magnetizer. The acquired IRM moment was measured by a Molspin spinner magnetometer.

Magnetic extracts of some samples separated by using a hand magnet were observed under a scanning electron microscope (Leo SEM 1450VP) after coating with carbon. Major element composition of selective grains was measured with an Oxford INCA EDS 200 microanalysis system linked to SEM, the details of which are given in Gautam et al. (2004b).

\subsection{Chemical analysis}

Twenty samples of dust-loaded leaves with varying $\chi$ were oven-dried at $75^{\circ} \mathrm{C}$ for $48 \mathrm{hrs}$., then ashed at $500^{\circ} \mathrm{C}$ for $2 \mathrm{hrs}$ and about $0.5 \mathrm{~g}$ of ash was digested for metals by $5 \mathrm{ml}$ aqua regia (conc. $\mathrm{HCl}$ to $\mathrm{HNO}_{3}$ ratio of 2:1) in a Kjeldatherm system (at $140^{\circ} \mathrm{C}, 2$ hrs.). A Perkin-Elmer M1100 atomic absorption spectrophotometer of the Department of Geography, University of Tübingen was used to analyze the pseudo-total contents of $\mathrm{Cd}, \mathrm{Cu}, \mathrm{Co}, \mathrm{Cr}, \mathrm{Fe}, \mathrm{Mn}, \mathrm{Ni}, \mathrm{Pb}, \mathrm{Zn}$ using a standard procedure (Ure, 1995).

In order to compare the measured quantities, both susceptibility and HM contents were recalculated on oven-dried mass basis. This involved: (i) subtraction of the susceptibility contribution of the water content from $\chi$ to obtain $\chi_{\mathrm{d}}$ following Walden et al. (1999); and (ii) reduction of the HM contents measured for ash to the oven-dried sample taking into account the mass lost upon ashing. 


\section{Magnetic Properties and Heavy Metal Chemistry}

\subsection{Magnetic susceptibility}

A brief summary on $\chi$ of all dust-loaded leaf samples according to type of trees is given in Table 1. Cypress offers maximum range $\left(\chi_{\max }-\chi_{\min }\right)$ followed by silky oak and bottlebrush. It has the lowest median and spread as indicated by the interquartile range. Silky oak and bottlebrush have median values close to each other but the former has a larger spread. Although direct comparison may not be well justified, the median values suggest that the dust-loaded leaves may be as strong as the fine-grained black clay/silt sediments, constituting the Kathmandu valley fluvio-lacustrine sediments, which yield (5.8-11.2) $\times 10^{-8}$ $\mathrm{m}^{3} \mathrm{~kg}^{-1}$ and a mean of $8.2 \times 10^{-8} \mathrm{~m}^{3} \mathrm{~kg}^{-1}$ (Gautam, unpublished data).

Two major road profiles shown in Fig. 2 reveal remarkable regularities in the susceptibility distribution. The Ring Road profile (Fig. 2a) exhibits a smooth susceptibility variation irrespective of the tree type (silky oak or bottlebrush) and the presence of anomalous zones, of distinctly high $\chi\left(>20 \times 10^{-8}\right)$ $\left.\mathrm{m}^{3} \mathrm{~kg}^{-1}\right)$, accompanied by flanks characterized by moderate $\chi\left(10-15 \times 10^{-8} \mathrm{~m}^{3} \mathrm{~kg}^{-1}\right)$. Two wide anomalous zones correspond to the areas around the main bus station and a rather long road sector, situated between Balkhu and Kalanki, where the TATA trucks spewing up black smokes are commonly parked along the roadsides. In the Kalanki - Tinkune profile, for which only data for cypress are shown (Fig. 2b), $\chi$ has a much wider range that can be explained by its inverse relationship with the distance of sampled trees from the major road axis. The two clusters of trees, located at appreciable distances from the road, to the West of Kalimati and near Baneshwar have correspondingly low susceptibilities (0.01-5 x $\left.10^{-8} \mathrm{~m}^{3} \mathrm{~kg}^{-1}\right)$. The highest values observed near Kalanki correspond to the road sector with relatively steep slopes. In general, the average susceptibility along the inner road is lower than along the Ring Road, which might be explained in terms of a larger volume of traffic as well as the probably a higher dust trapping potential of the silky oak and bottle brush than the cypress.

Along roadsides in the city core area, high $\chi$ occurs close to the road junctions (e.g. near the clock tower, Fig. 3). Increase in $\chi$ is observed while moving towards roads from recreational parks (Fig. 3). Moderate values characterize trees in open spaces, which are prone to dust supply from nearby roads or exposed grounds. This is shown by a profile across the Ratna Park, where most trees in the row form a wind barrier as well as an effective trap for dust incoming from the adjacent open ground (Fig. 3).

\subsection{Magneto-mineralogical characterization}

a) IRM characteristics

In several specimens sampled from different localities, the IRM acquired at $0.1 \mathrm{~T}$ and $0.3 \mathrm{~T}$ is about $70 \%$ and $85-90 \%$ of the total magnitude acquired at $2.5 \mathrm{~T}$, respectively (Fig. 4a). It means that soft magnetic minerals (magnetite and probably maghemite) contribute significantly (Fig. 4b,c). Judging from $10 \%$ to $20 \%$ of IRM acquired within 0.3 and $2.5 \mathrm{~T}$, a high content of a harder magnetic phase is confirmed. Most likely the hard phase is hematite. It probably comes from the bricks which are known to contribute significantly to the susceptibility of urban soils (Gautam et al., 2004b).

\section{b) Scanning electron microscopy (SEM) images}

Microscopy of magnetic extracts from the dust contained in tree leaves reveals basically two morphologies of grains (Fig. 5). Firstly euhedral to anhedral crystalline grains mostly derived from rock sources and secondly spherical grains. The isolated spherical grains exhibit orange peel and/or framboidal textures (Fig. 5a,c). Agglomerates exhibit welded (to clusters) textures (Fig. 5b). The diameter of isolated spherules is typically $2-20 \mu \mathrm{m}$. However, the linear dimension may exceed $100 \mu \mathrm{m}$ for agglomerates (Fig. 
5c). In terms of chemistry (Table 2), the isolated grains have the following typical composition: Fe (76-77 wt $\%)$ and $\mathrm{O}(22-23 \mathrm{wt} \%)$, irrespective of the grain geometry. For the spots within the agglomerated grain, the contents of $\mathrm{Fe}$ and $\mathrm{O}$ are $70-71 \mathrm{wt} \%$ and $>24 \mathrm{wt} \%$ (points 7,8 in Fig. $5 \mathrm{~b}$ and Table 2). Spherules contain traces of $\mathrm{Co}$ and $\mathrm{Tb}$, whereas the agglomerate contains $\mathrm{S}$ and $\mathrm{Cl}$. The lower values of $\mathrm{Fe}$ as well as the presence of $\mathrm{Mg}, \mathrm{Al}, \mathrm{Si}$, Ti etc. in some analyses (1, 5, 6 in Fig. 5 and Table 2) may be the result of contamination of the analyzed spots by background silicate material. In general, the chemical composition of the isolated grains is close to that of pure magnetite.

\subsection{Heavy metal chemistry and their correlation with susceptibility}

The ranges of metal contents measured for a set of 20 samples are as follows: $0.08-1.33 \mathrm{wt} \%$ of Fe, 18.3-281.9 ppm of Mn, 15.9-195.2 ppm of Zn, 4.7-41.5 ppm of $\mathrm{Cu}, 1.8-38.4 \mathrm{ppm}$ of $\mathrm{Pb}, 0.6-8.1 \mathrm{ppm}$ of $\mathrm{Ni}$, and 1.7-6.4 ppm of $\mathrm{Cr}$. The exceptionally high contents of $\mathrm{Cr}$ (76.8 ppm), $\mathrm{Ni}(48.8 \mathrm{ppm})$ and $\mathrm{Pb}(46.1$ $\mathrm{ppm})$ for sample L114 are considered to be outliers and not included in these ranges. The maximum contents of $\mathrm{Co}$ and $\mathrm{Cd}$ were $4.1 \mathrm{ppm}$ and $1.2 \mathrm{ppm}$, respectively. Contents of $\mathrm{Co}$ and $\mathrm{Cd}$ were below 1.0 ppm in 12 and 17 samples, respectively, being mostly around the analytical detection limit. Hence, Co and $\mathrm{Cd}$ contents are not discussed further.

It is evident from the correlation matrix in Table 3 that the logarithmic $\chi_{\mathrm{d}}$ has significant linear relationship with metal contents: Pearson's correlation coefficient $r>0.8$ with, $\mathrm{Zn}, \mathrm{Fe}, \mathrm{Cr} ; \mathrm{r}>0.7$ with $\mathrm{Mn}$, $\mathrm{Cu}$; and $\mathrm{r}>0.6$ with $\mathrm{Pb}$, Ni. Among metals themselves, Fe exhibits very strong correlation $(\mathrm{r}>0.85)$ with $\mathrm{Mn}, \mathrm{Zn}$ and $\mathrm{Cr}$. Similarly, $\mathrm{Zn}, \mathrm{Cu}$ and $\mathrm{Pb}$ are strongly related among themselves with $\mathrm{r}=0.83-0.87$.

In order to judge how closely the variables (metal contents and susceptibility), are related to each other, a tree diagram is constructed using the single linkage distance ratio method (Fig. 6a). This interpretation is not unique but a reasonable description of the observed dataset. According to the diagram, the metals $\mathrm{Fe}, \mathrm{Zn}$ and $\mathrm{Cr}$ form a close cluster as do $\mathrm{Mn}$ and $\mathrm{Cu}$. Further, these two groups are closer to each other than with $\chi_{\mathrm{d}}$. $\mathrm{Pb}$ is relatively farther from all variables while $\mathrm{Ni}$ is removed farthest from all.

The linear relationship between a set of 3 urban elements $(\mathrm{Cu}, \mathrm{Pb}$ and $\mathrm{Zn}$, known to originate from vehicular pollution; e.g. de Miguel et al., 1997) and Fe with logarithmic $\chi_{d}$ is detailed in Fig. 6b. There are clearly two groups which show varying goodness of fit $\left(\mathrm{r}^{2}\right)$ but striking similarities in variation of contents with respect to susceptibility within each group are evident.

\section{Discussion and Conclusions}

The highest range of $\chi$ (Table 1) of the dust-loaded leaves of cypress trees, which are ubiquitous along the inner roads and recreational parks in Kathmandu, makes them suitable for magnetic bio-monitoring along profiles and also over selected areas. As the silky oak and bottlebrush yield comparable susceptibilities as shown by the Ring Road profile (Fig. 2a), the preference of one over the other will depend on the availability of the concerned trees. It is notable, however, that all three species offer reasonable contrasts in susceptibility that has significant correlation to the HM contents, especially the urban elements like $\mathrm{Cu}, \mathrm{Pb}$ and $\mathrm{Zn}$.

The observed maximum contents of urban elements in dust loaded leaves ( $\mathrm{Zn:} 195.2 \mathrm{ppm}, \mathrm{Cu}: 41.5$ ppm, $\mathrm{Pb}: 38.4 \mathrm{ppm}$ ) are enhanced by $232 \%, 122 \%$ and $240 \%$ with respect to the local background contents ( $\mathrm{Zn}: 84 \mathrm{ppm}, \mathrm{Cu}: 34 \mathrm{ppm}, \mathrm{Pb}: 16 \mathrm{ppm}$ ) for a soil profile at an urban background site in Kirtipur (Gautam et al. 2004a). Their magnitudes are, however, low compared to the maximum contents for Bagmati river sediments ( $\mathrm{Zn}: 277.0 \mathrm{ppm}, \mathrm{Cu}: 63.6 \mathrm{ppm}$, and $\mathrm{Pb}: 173.3 \mathrm{ppm}$ ) obtained by similar type of analysis (Devkota, 2001). Although direct comparisons of the metal contents in soils, river sediments and leaves are problematic due to many factors (e.g., differences in timescales, depositional/removal 
processes and the differences in areas averaged by the samples), they show that temporary accumulations of PM in roadside tree leaves may give rise to very high levels of metal contents.

The magnetic spherules are attributed to anthropogenic input, arising from any type of combustion related to vehicles as shown also by dust samples taken from the road surface or the rubber plant leaves at $<0.5 \mathrm{~m}$ height (Gautam et al., 2004b). Palmgren et al. (2003) found that the tailpipe emissions give rise to fine and ultrafine particles with modal aerodynamic diameters of 0.1-2 and 0.03-0.1 $\mu \mathrm{m}$, respectively, whereas abrasion-related particles yield rather coarse modes $(>2 \mu \mathrm{m})$. According to Matzka and Maher (1999), the grain size was found to lie between 0.3 and $3 \mu \mathrm{m}$ interpreted in favour of derivation of such fine particles from vehicle exhaust rather than friction wear or resuspended road dust. Despite the relatively large predominant size $(2-20 \mu \mathrm{m})$ of spherules observed in this study, we attribute them to the tailpipe emissions as they occur along the roadside trees which are far away from industrial sources. Possibility of generation of large-sized particles through combustion in vehicles is also supported by recent findings of: (i) large-sized magnetite (up to $8 \mu \mathrm{m}$ diameter) formed by burning $\mathrm{FeS}_{2}$ containing fossil fuel (Flanders, 1999); and (ii) a significant amount of 7-50 $\mu \mathrm{m}$ (with a maximum of $300 \mu \mathrm{m}$ ) sized spherules in road dust from Visakhapatnam in India (Goddu et al., 2004). Most of the euhedral to subhedral grains yielding magnetite-like mineralogy are attributed to lithogenic origin (Gautam et al., 2004b).

The dust accumulation in tree leaves took place mostly after the post-monsoon (beginning of October, 2001) until the sampling period (first half of February, 2002). The measured quantities depend on the degree of pollution governed by a variety of time- and space dependent factors: amount of particles of anthropogenic and lithogenic origin; efficiency of deposition of particles in leaves as a function of the distance from road (Matzka and Maher, 1999), height and areal coverage of leaves; intensity of precipitation; intensity and direction of wind; degree of disturbance by living beings such as humans, animals and birds, etc. Lack of adequate knowledge on all these factors makes the interpretation of minute susceptibility variations difficult. In such case, it may be sometimes more realistic to judge the variations in qualitative terms by grouping into susceptibility classes as shown in (Fig. 3). A significant linear relationship between the HM contents and susceptibility proves that the latter serves as an effective proxy of the metallic pollution (especially by $\mathrm{Pb}, \mathrm{Cu}, \mathrm{Zn}$ originating mainly from vehicular sources).

Occurrence of relatively higher metal contents in sides of trees proximal to roads than in the distal sides, and the ability of trees to draw dust and hence reduce particulate concentrations at respirable heights may be a positive feature (e.g., Matzka and Maher, 1999). This is indeed true for trees along sides of highways with spacious lawns and houses located reasonably away from the roads. However, in urban areas like in Kathmandu with narrow roadsides with human activity occurring in proximity of roads, the capability of trees to collect and hold harmful particulate matter, on a temporary basis, may have adverse health effects on the residents.

In conclusion, magnetic susceptibility measurements of leaves are effective in identifying pollution hot spots with marked input of magnetic materials derived from anthropogenic traffic-related pollution. Because of the good correlation of susceptibility with the heavy metals related to urbanization, the former serves as a proxy for metallic pollution. Therefore, use of susceptibility-based biomonitoring technique should be considered for temporal (short-term, mostly up to several months) and spatial assessment of pollution in cities, like Kathmandu, where traffic-related problems are ever increasing. With proper calibration of susceptibility with metal contents for the most characteristic tree type available, this method can be used for detailed monitoring of anomalously polluted areas. 


\section{Acknowledgements}

PG acknowledges a Forster Research Fellowship by Alexander von Humboldt Foundation and the $21^{\text {st }}$ Century COE Program for Neo-Science of Natural History. We thank Rolf Beck (University of Tübingen) for expert advice during chemical analyses and Sabita Poudel (Tribhuvan University) for assisting us with identification of tree types.

\section{References}

De Miguel, E., Llamas, J.F., Chacón E., Berg, T., Larssen, S., Røyset, O., Vadset, M., 1997. Origin and patterns of distribution of trace elements in street dust: unleaded petrol and urban lead. Atmospheric Environment 31 (17), 2733-2740.

Devkota, D., 2001. Total and extractable (mobilizable and mobile) heavy metals in the Bagmati river sediment of Kathmandu, Nepal. A Journal of the Environment 6 (7), 34-51.

Fang, G-C., Chang, C-N., Wu Y-S., Chen, M-H., Ho, T-T., Huang S-H., 2004. A study of metallic elements at suburban and industrial regions in central Taiwan during 2003-2003. Atmospheric Research 70, 131-142.

Flanders, P.J., 1999. Identifying a fly ash at a distance from fossil fuel power stations. Environmental Science and Technology 33, 528-532.

Gautam, P., Blaha, U., Appel, E., 2004a. Integration of magnetic properties and heavy metal chemistry to quantify environmental pollution in urban soils, Kathmandu, Nepal. Himalayan Journal of Sciences 2(4), 140-141.

Gautam, P., Blaha, U., Appel, E., Neupane, G., 2004b. Environmental magnetic approach towards the quantification of pollution in Kathmandu urban area, Nepal. Physics and Chemistry of the Earth 29/13-14, 973-984. doi:10.1016/j.pce.2004.02.001

Goddu S.R., Appel, E., Jordanova, D., Wehland, F., 2004. Magnetic properties of road dust from Visakhapatnam (India) - relationship to industrial pollution and road traffic. Physics and Chemistry of the Earth 29/13-14, 985-995. doi:10.1016/j.pce.2004.02.002

Hanesch, M., Scholger, R., 2002. Mapping of heavy metal loadings in soils by means of magnetic susceptibility measurements. Environmental Geology 42, 857-870.

Hanesch, M., Scholger, R., Rey, D., 2003. Mapping dust distribution around an industrial site by measuring magnetic parameters of tree leaves. Atmospheric Environment 37, 5125-5133.

Hoffmann, V., Knab, M., Appel, E., 1999. Magnetic susceptibility mapping of roadside pollution. Journal of Geochemical Exploration 66, 313-326.

KEVA, 2003. Health Impacts of Kathmandu's Air Pollution. Report submitted to Kathmandu Electrical Vehicle Alliance (KEVA) by Clean Energy Nepal and Environmental and Public Health Organization, Kathmandu, 87pp. (unpubl.)

Knab, M., Appel, E., Hoffmann, V., 2003. The anthropogenic dust load of coniferous tree needles in the Black Forest -area, forest area, SW Germany: an approach using magnetic susceptibility (MS). In: Abstracts, XXIII General Assembly of the International Union of Geodesy and Geophysics, Sapporo, GAI.02/01A/A16-007. A.261.

Kruiver, P.K., Dekkers, M.J., Heslop, D., 2001. Quantification of magnetic coercivity components by the analysis of acquisition curves of isothermal remanent magnetization. Earth and Planetary Science Letters 189, 269-276.

Matzka, J., Maher, B.A., 1999. Magnetic biomonitoring of roadside tree leaves: identification of spatial and temporal variations in vehicle-derived particulates. Atmos. Environ. 33, 4565-4569. 
MOPE Nepal, 2004. http://www.mope.gov.np/environment/air.php and http://mope.gov.np/mopepollution/

Moreno, E., Sagnotti, L., Winkler, A., Dinarès-Turell, J., Cascella, A., 2003. Air pollution survey in Rome using magnetic properties of tree leaves. Geophysical Research Abstracts, Vol. 5, 02551, European Geophysical Society.

Muxworthy, A.R., Schmidbauer, E., Petersen, N., 2002. Magnetic properties and Mössbauer spectra of urban atmospheric particulate matter: a case study from Munich, Germany. Geophysical Journal International 150, 558-570.

NESS, 2001. Air quality database of Nepal. Nepal Environmental and Scientific Services Co., special issue, Kathmandu.

Palmgren, F., Wåhlin, P. Kildesø, J., Afshari, A., Fogh. C.L., 2003. Characterization of particle emissions from the driving car fleet and the contribution to ambient and indoor particle concentrations. Physics and Chemistry of the Earth 28, 327-334.

Petrovsky, E., Ellwood B.B., 1999. Magnetic monitoring of pollution of air, land and waters. In: Maher, B.A., Thompson, R. (Eds.), Quaternary Climates, Environments and Magnetism, Cambridge University Press, Cambridge, pp. 279-322.

Samet, J.M., Francesca, D., Curriero, F.C., Coursac, I., Zeger, L. Scott, 2000. Fine particulate air pollution and mortality in 20 US cities, 1987-1994. New England Journal of Medicine 343 , 1742-9.

Schädlich, G., Weissflog, L., Schuurmann, G., 1995. Magnetic susceptibility in conifer needles as indicator of fly ash deposition. Fresenius Environmental Bulletin 4(1), 1995, 7-12.

Shrestha, B., Pradhan, S., 2000. Kathmandu Valley GIS database. ICIMOD, Kathmandu.

Ure, A.M., 1995. Methods of analysis for heavy metals in soils. In: Alloway, B.J. (Ed.), Heavy metals in soils (second edition), Blackie Academic \& Professional, London, pp. 59-100,.

Walden, J., Oldfield, F. and Smith, J.P. (Eds.) 1999. Environmental magnetism: a practical guide, Technical Guide Series, No. 6, Quaternary Research Association, London, pp. 250.

Fig. 1. Sketch maps showing the locations of trees sampled for the dust-loaded leaves. Location of the three districts of Kathmandu Valley is indicated in the index map in upper right corner of the map. The greater Kathmandu urban area comprising Kathmandu and Patan cities is shown by light shading. The light and dark lines indicate the major road network and major rivers marking district boundaries. The Ratna Park area at the heart of the Kathmandu city investigated in more detail (Fig. 3) is marked. Symbols (plus, multiplication and dot) stand for the location of sampled trees (silky oak, bottlebrush, cypress) and susceptibility variation in them along two major profiles is shown in Fig. 2. Samples from 5 sites labelled as L70, L94, L106, L114 and L174 used to describe magnetic minerals and chemistry in Figs. 4 and 5 are indicated by arrows. The background map was modified from Shrestha and Pradhan (2000). 


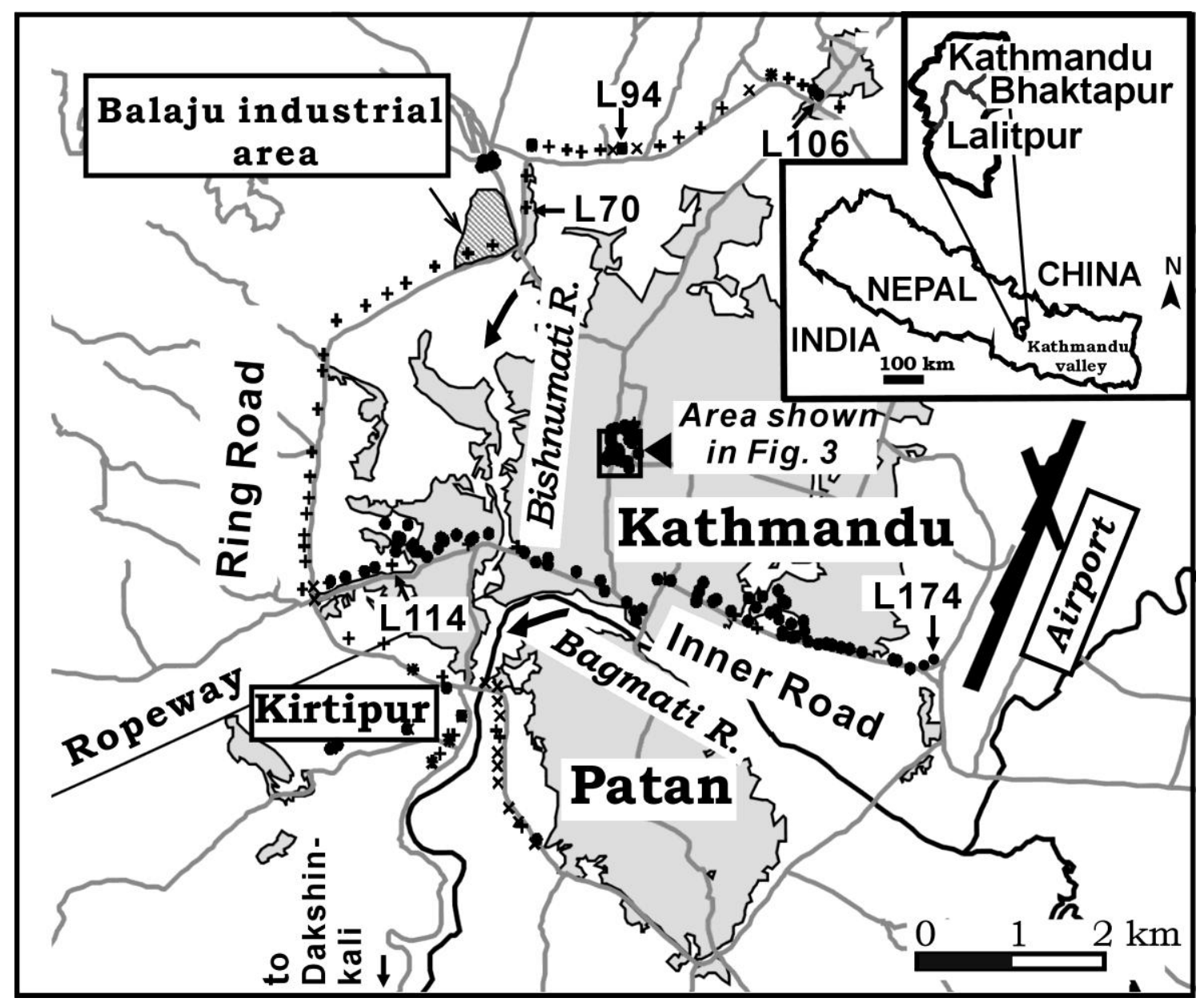


Fig. 2. Magnetic susceptibility $(\chi)$ of the dust-loaded leaves from trees, sampled along the two major road profiles. For the Ring Road profile (Fig. 2a, left side), a $\chi$ vs. latitude plot is given. For the inner road profile (Fig. 2b, upper part), between Kalanki and Tinkune, a $\chi$ vs. longitude plot better reflects the variation. The shaded rectangles, in both profiles, mark sectors showing consistently high $\chi$. In contrast, the points included within ovals mark the relatively low $\chi$ which can be explained in terms of the distance of the sites from the road axis.

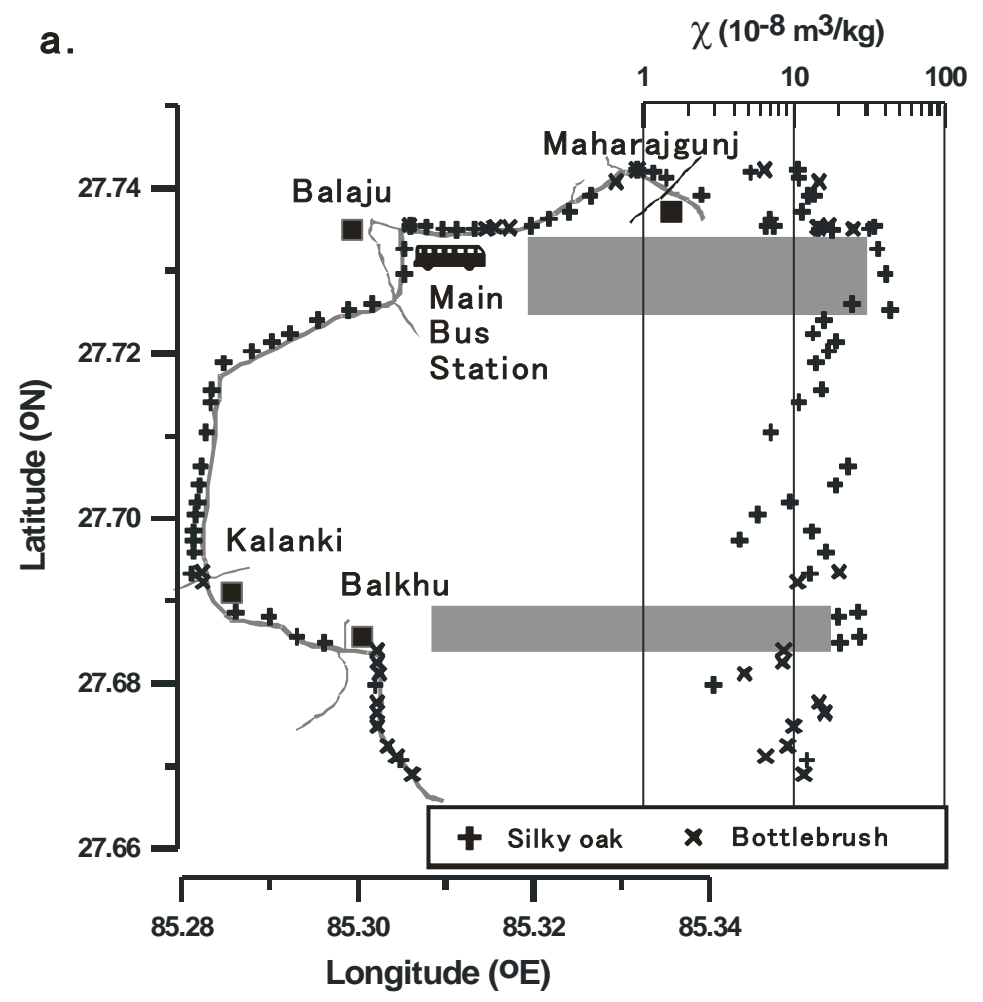

b.

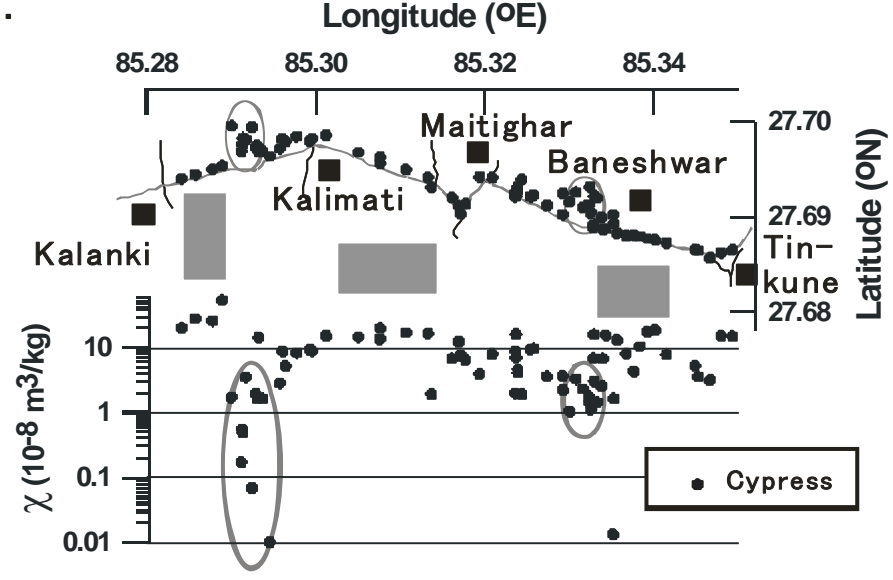


Fig. 3. Magnetic susceptibility of the dust-loaded leaves around the Ratna Park - Rani Pokhari, in the core urban area. The rows of trees along a foot trail in between the Ratna Park and the open-air theatre has been shown in map as well as profile. The size of the symbols (filled circles: cypress; open circles: silky oak) is proportional to the susceptibility magnitude as shown in the class legend. Elevated values occur near the road intersections. Within the Ratna Park area, trees located in the innermost parts possess the lowest $\chi$.

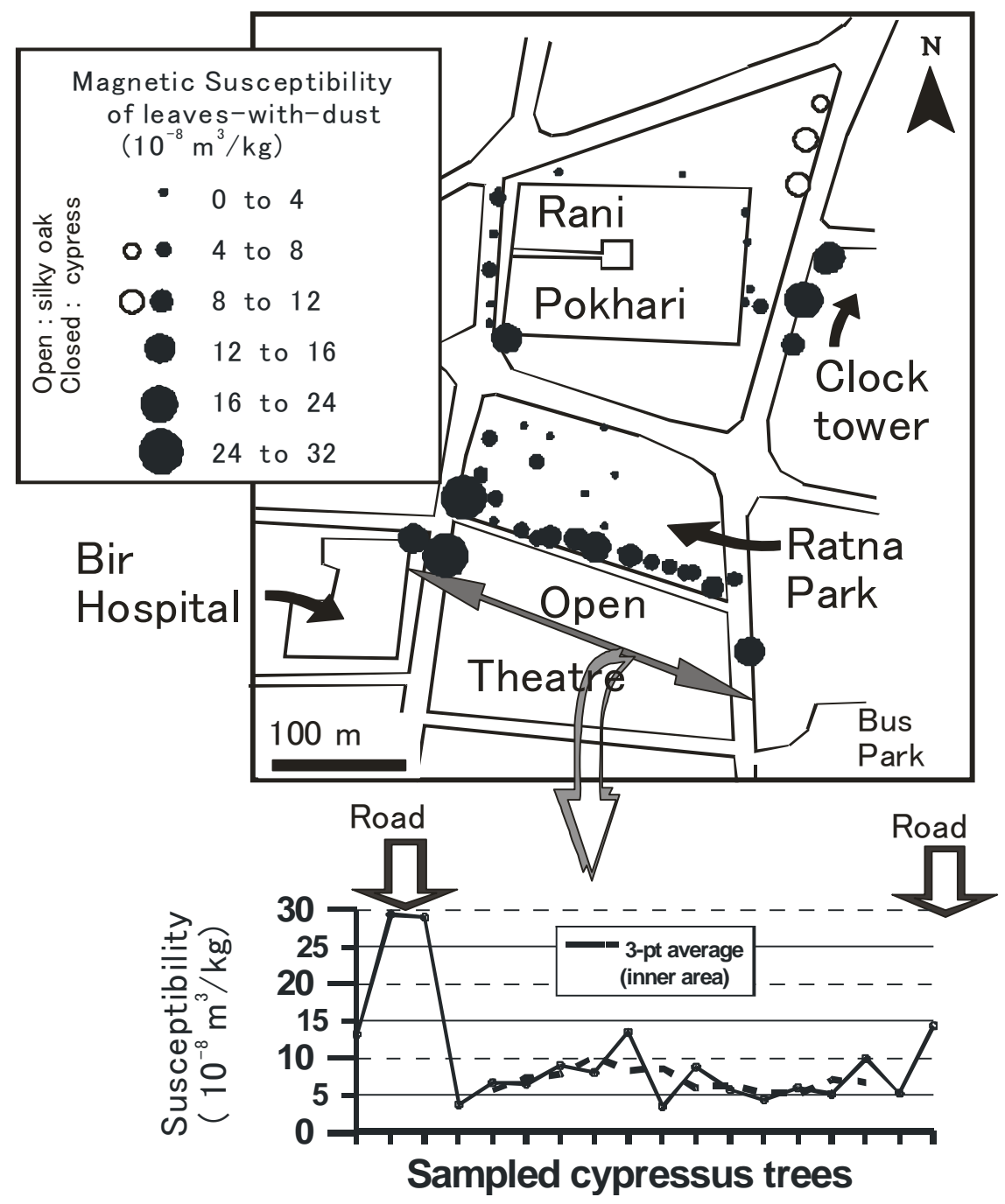


Fig. 4. Isothermal remanent magnetization (IRM) data for the dust-loaded leaves. (a) IRM acquisition curves for three samples (see Fig. 1, for locations), exhibiting remarkably similar shapes. (b, c) Results of component modelling for a sample, following Kruiver et al. (2001). The IRM magnitude and its gradient along with the modelled median acquisition field $\left(\mathrm{B}_{1 / 2}\right)$ values, indicated by arrows, as contributing to the curves and the respective logarithmic standard deviations $(\operatorname{lgS})$, are shown.

a.

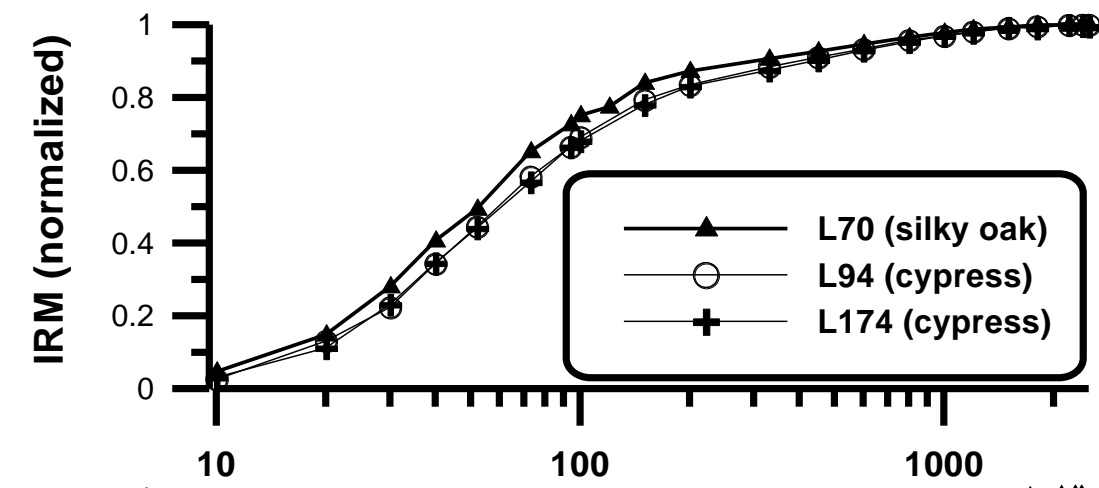

b.

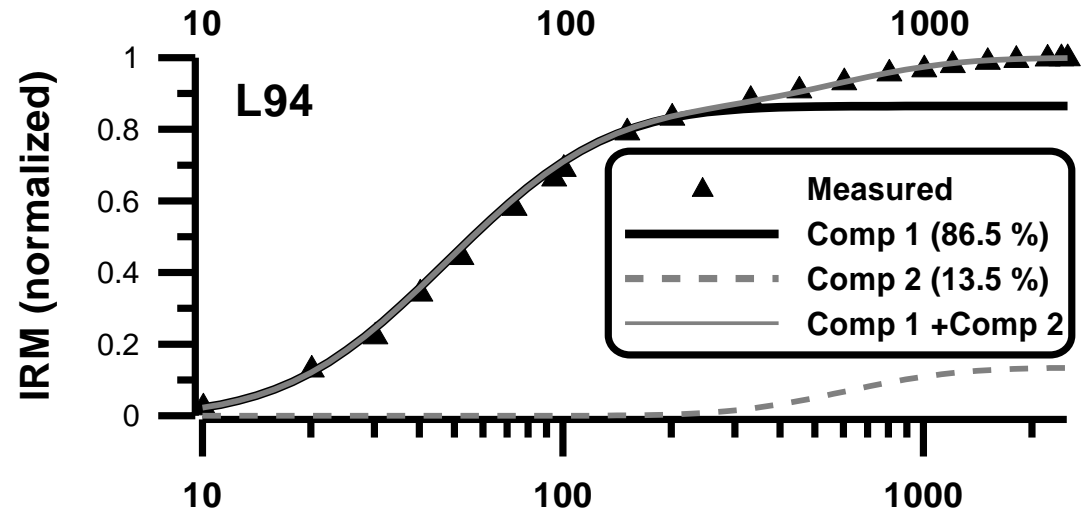

c.

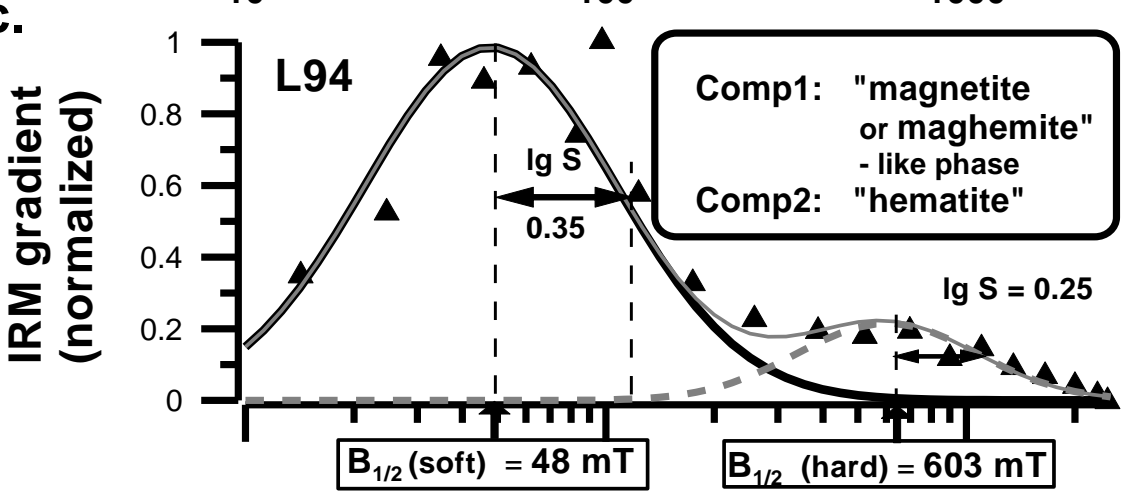

Applied Field, B (mT) 
Fig. 5. Back-scattered images of the magnetic grains observed in magnetic extracts of the leaf-dust. The sample locations are given in Fig. 1. The magnetic material can be classified roughly into two groups: (i) isolated relatively fine spherules and agglomerates formed by aggregation or welding of smaller spherules, of anthropogenic origin, and (ii) euhedral to subhedral grains of lithogenic origin. Note the relatively large magnetic spherule with distinct orange-peel structure indicative of combustion. Numbered symbols (+) are spots of energy-dispersive X-ray analyses, data for which are given in Table 2.
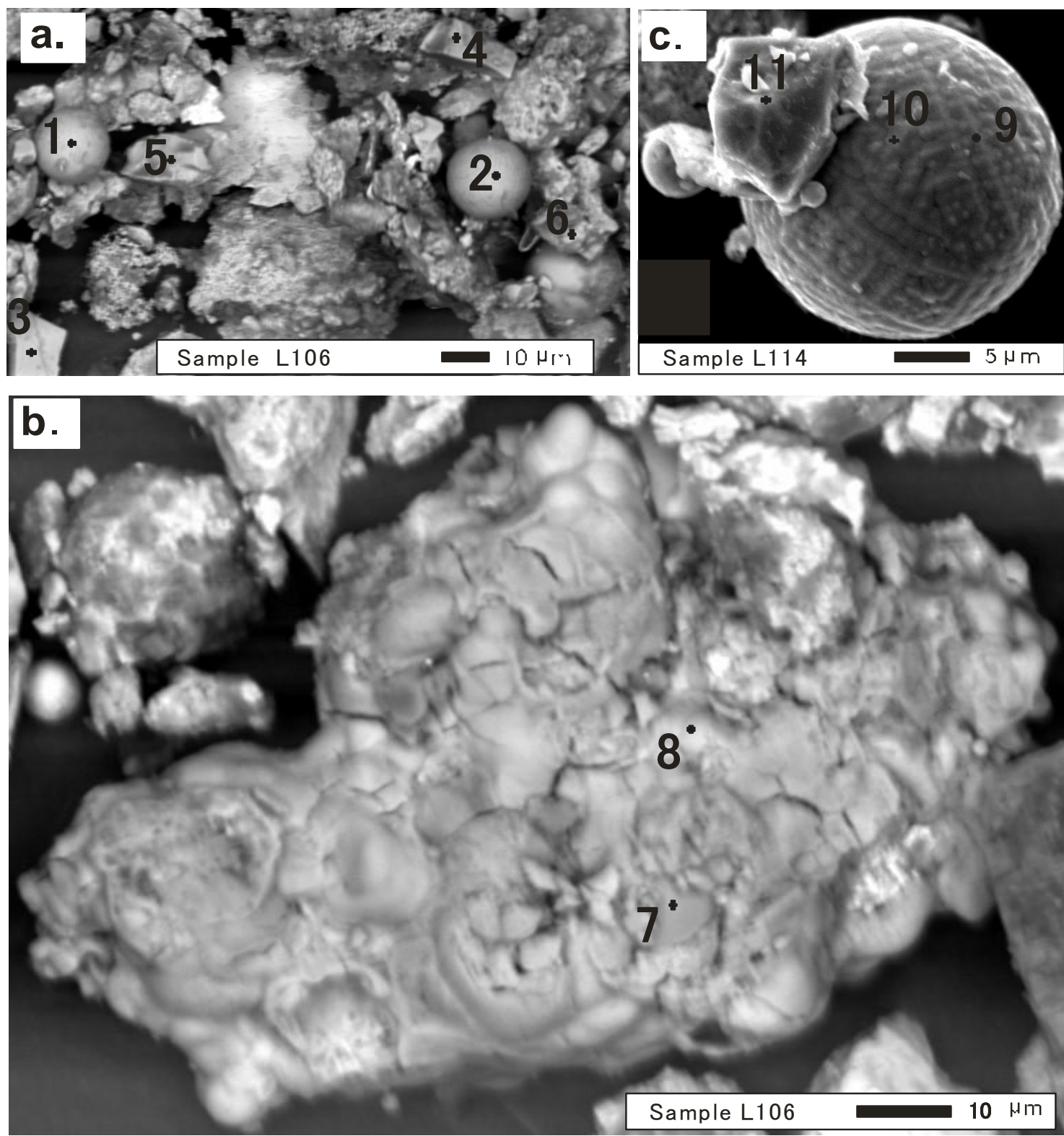

Gautam et al. fig 5 
Fig. 6. (a) A tree diagram, derived from cluster analysis, depicting the correlation between HM contents and susceptibility based on single linkage distance. (b) Linear regression analysis between selected heavy metals and magnetic susceptibility and the regression equations for estimating metal contents from the magnetic susceptibility $\left(\chi_{\mathrm{d}}\right)$. The coefficient determination $\left(\mathrm{r}^{2}\right)$ gives the goodness of fit of the regression line.

a.

Single Linkage

1-Pearson's correlation coefficient ( $r$ )
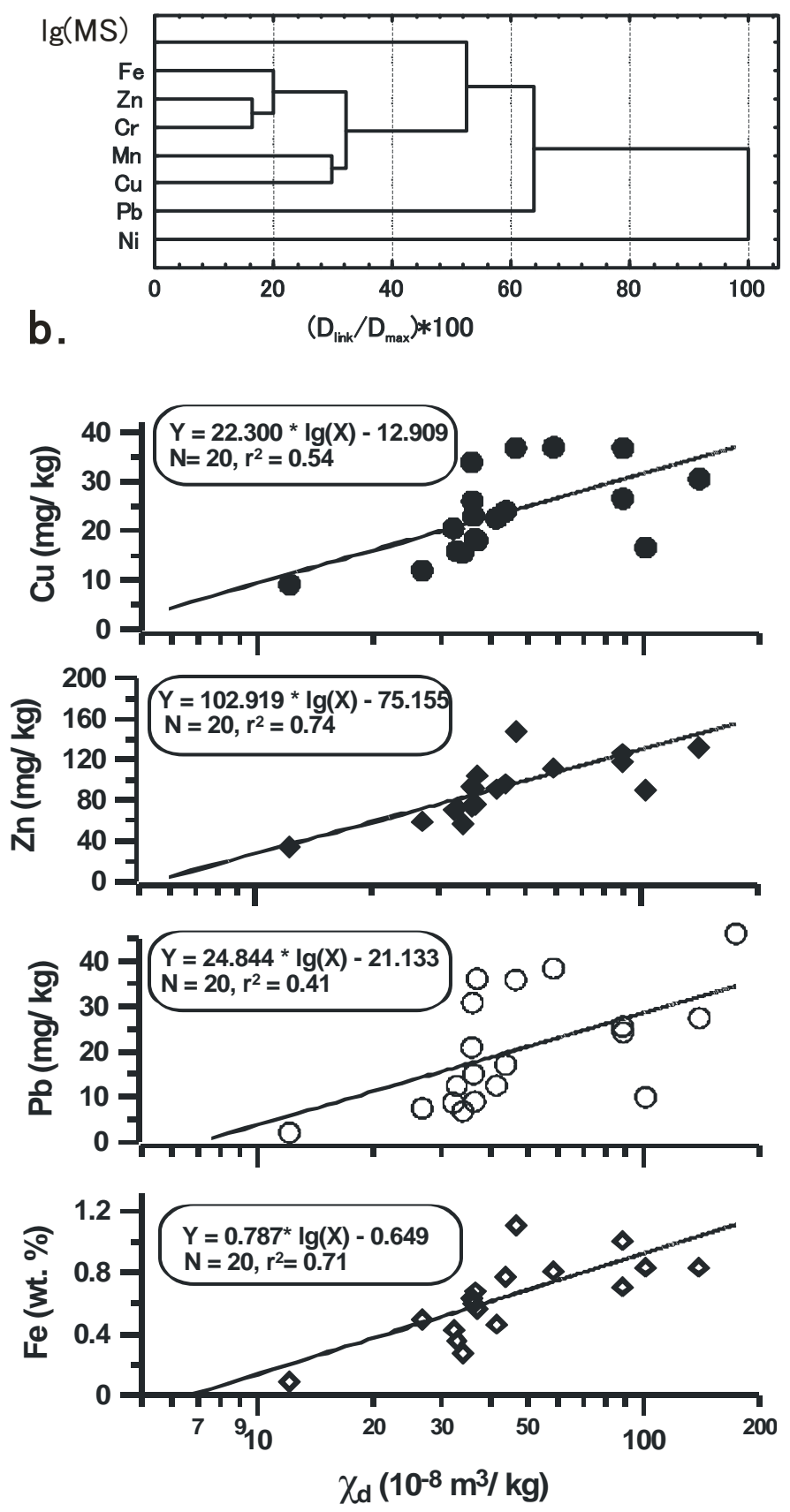
Table 1. Magnetic susceptibility data by dust-loaded leaves by tree types

\begin{tabular}{|c|c|c|c|c|c|c|c|}
\hline \multirow[b]{3}{*}{ Tree type } & \multirow{3}{*}{$\begin{array}{l}\text { No. of } \\
\text { samples }\end{array}$} & \multicolumn{6}{|c|}{ MS $\left(10^{-8} \mathrm{~m}^{3} \mathrm{~kg}^{-1}\right)$} \\
\hline & & \multirow[b]{2}{*}{ Min. } & \multicolumn{3}{|c|}{ Quartiles } & \multirow{2}{*}{$\begin{array}{c}\text { Range } \\
\text { (Max-Min) }\end{array}$} & \multirow{2}{*}{$\begin{array}{l}\text { Interquart } \\
\text { le Range } \\
\text { (Q3-Q1) }\end{array}$} \\
\hline & & & Q1 (25\%) & $\begin{array}{l}\text { Median } \\
(50 \%) \\
\end{array}$ & Q3 (75\%) & & \\
\hline $\begin{array}{l}\text { Himalayan } \\
\text { cypress }\end{array}$ & 142 & 0.01 & 2.23 & 5.27 & 10 & 53.97 & 7.77 \\
\hline Silky oak & 55 & 2.75 & 7.55 & 13.08 & 18.83 & 40.33 & 11.28 \\
\hline Bottlebrush & 24 & 1.12 & 7.12 & 10.31 & 15.31 & 23.49 & 8.19 \\
\hline
\end{tabular}

Table 2 Energy-dispersive x-ray analytical data (wt. \%) on magnetic grains constituting the dust in leaves

\begin{tabular}{|c|c|c|c|c|c|c|c|c|c|c|c|}
\hline \multirow{3}{*}{$\begin{array}{l}\text { Points*/ } \\
\text { Element }\end{array}$} & \multicolumn{8}{|c|}{ L106 } & \multicolumn{3}{|c|}{ L114 } \\
\hline & \multicolumn{2}{|c|}{ Spherules } & \multicolumn{4}{|c|}{ Nonspherical grains } & \multicolumn{2}{|c|}{ Agglomerate } & \multicolumn{2}{|c|}{ Spherules } & \multirow{2}{*}{$\frac{\text { Nonsph. gr. }}{11}$} \\
\hline & $\overline{1}$ & 2 & $\overline{3}$ & 4 & 5 & 6 & $\overline{7}$ & 8 & $\overline{9}$ & 10 & \\
\hline $\mathbf{F e}$ & 69.77 & 76.98 & 76.24 & 77.44 & 74.75 & 72.77 & 70.12 & 70.88 & 77.24 & 76.69 & 77.44 \\
\hline $\mathrm{Mg}$ & 0.63 & - & - & - & - & 0.40 & - & - & - & - & - \\
\hline $\mathrm{Al}$ & 0.97 & - & 0.35 & 0.10 & 0.41 & 0.41 & - & 0.33 & - & - & - \\
\hline $\mathrm{Si}$ & 1.39 & 0.22 & 0.46 & 0.09 & 0.62 & 0.58 & 0.73 & 0.72 & 0.29 & 0.23 & 0.09 \\
\hline K & 0.46 & - & - & - & - & 0.24 & - & 0.32 & - & - & - \\
\hline $\mathrm{Ti}$ & 0.92 & - & - & - & - & - & - & - & - & - & - \\
\hline $\mathrm{Ca}$ & - & - & 0.20 & - & 0.87 & 0.86 & 1.35 & 1.01 & & & \\
\hline Co & - & - & - & - & - & - & - & - & - & 0.67 & - \\
\hline $\mathrm{Tb}$ & 2.00 & - & - & - & - & - & - & - & - & - & - \\
\hline Mn & - & - & - & - & - & 0.62 & 0.83 & 0.60 & - & - & - \\
\hline S & - & - & - & - & 0.21 & & 1.91 & 1.44 & - & - & - \\
\hline $\mathrm{P}$ & - & - & - & - & - & 0.61 & - & - & - & - & - \\
\hline $\mathrm{Br}$ & - & 0.50 & - & - & - & - & - & - & - & - & 0.17 \\
\hline $\mathrm{Cl}$ & - & - & - & - & - & - & 0.49 & 0.45 & - & - & - \\
\hline $\mathbf{O}$ & 23.86 & 22.30 & 22.75 & 22.37 & 23.15 & 23.50 & 24.57 & 24.23 & 22.46 & 22.41 & 22.29 \\
\hline Total & 100.00 & 100.00 & 100.00 & 100.00 & 100.01 & 99.99 & 100.00 & 99.98 & 99.99 & 100.00 & 99.99 \\
\hline
\end{tabular}


Table 3

Correlation matrix for magnetic susceptibility and heavy metal contents $(\mathrm{N}=20)$

\begin{tabular}{|c|c|c|c|c|c|c|c|c|}
\hline & $\lg (\mathrm{MS})$ & $\mathrm{Fe}$ & $\mathrm{Mn}$ & $\mathrm{Zn}$ & $\mathrm{Cu}$ & $\mathrm{Pb}$ & $\mathrm{Ni}$ & $\mathrm{Cr}$ \\
\hline$\overline{\lg (\mathrm{MS})}$ & 1.00 & & & & & & & \\
\hline $\mathrm{Fe}$ & $0.84(.000)$ & 1.00 & & & & & & \\
\hline $\mathrm{Mn}$ & $0.76(.000)$ & $0.91(.000)$ & 1.00 & & & & & \\
\hline $\mathrm{Zn}$ & $0.86(.000)$ & $0.92(.000)$ & $0.83(.000)$ & 1.00 & & & & \\
\hline $\mathrm{Cu}$ & $0.74(.000)$ & $0.86(.000)$ & $0.92(.000)$ & $0.87(.000)$ & 1.00 & & & \\
\hline $\mathrm{Pb}$ & $0.64(.002)$ & $0.78(.000)$ & $0.76(.000)$ & $0.85(.000)$ & $0.83(.000)$ & 1.00 & & \\
\hline $\mathrm{Ni}$ & $0.60(.006)$ & $0.57(.012)$ & $0.53(.021)$ & $0.67(.002)$ & $0.61(.006)$ & $0.68(.001)$ & 1.00 & \\
\hline $\mathrm{Cr}$ & $0.80(.000)$ & $0.94(.000)$ & $0.79(.000)$ & $0.95(.000)$ & $0.79(.000)$ & $0.72(.001)$ & $0.66(.002)$ & 1.00 \\
\hline
\end{tabular}

For each pair, the Pearson's product-moment correlation $\mathrm{r}$ is given with the level of singificance $\mathrm{p}$ (in

brackets) 